\title{
Erratum to: Enhancement of deep-sea floor images obtained by an underwater vehicle and its evaluation by crab recognition
}

\author{
Jonghyun Ahn ${ }^{1} \cdot$ Shinsuke Yasukawa ${ }^{1} \cdot$ Takashi Sonoda $^{1} \cdot$ Tamaki Ura $^{1}$. \\ Kazuo Ishii ${ }^{1}$
}

Published online: 18 April 2017

(C) JASNAOE 2017

\section{Erratum to: J Mar Sci Technol DOI 10.1007/s00773-017-0442-1}

In the original publication, references are ordered incorrectly. The corrected list of references is given in this Erratum.

\section{References}

1. Junku Y, Ura T, Bekey G (1996) Underwater robots. Springer US, New York

2. Whitcomb LL (2000) Underwater robotics: out of the research laboratory and into the field. In: IEEE international conference on ICRA'00, vol 1, pp 709-716

3. Nishida Y, Ura T, Sakamaki T, Kojima J, Ito Y, Kim K (2013) Hovering type AUV "Tuna-Sand" and its surveys on Smith caldera in Izu-Ogasawara ocean area. 2013 OCEANS-San Diego. IEEE, pp 1-5

4. Maki T, Sato Y, Matsuda T, Shiroku RT, Sakamaki T (2014) AUV Tri-TON 2: an intelligent platform for detailed survey of hydrothermal vent fields. IEEE/OES autonomous underwater vehicles (AUV), pp 1-5

5. Nishida Y, Nagahashi K, Sato T, Bodenmann A, Thornton B, Asada A, Ura T (2015) Development of an autonomous underwater vehicle for survey of cobalt-rich manganese crust. OCEANS 2015-MTS/IEEE Washington, pp 1-5

6. Ura T (2013) Observation of deep seafloor by autonomous underwater vehicle. IJMS 42(8):1028-1033

7. Bewley M, Douillard B, Nourani-Vatani N, Friedman A, Pizarro O, Williams S (2012) Automated species detection: an

The online version of the original article can be found under doi:10.1007/s00773-017-0442-1.

Jonghyun Ahn

ahn-jonghyun@edu.brain.kyutech.ac.jp

1 Kyushu Institute of Technology, Fukuoka, Japan experimental approach to kelp detection from sea-floor AUV images. In: Australasian conference on robotics and automation, pp $1-10$

8. Boudhane M, Nsiri B (2016) Underwater image processing method for fish localization and detection in submarine environment. J Vis Commun Image Represent 39:226-238

9. Hulburt EO (1945) Optics of distilled and natural water. J Opt Soc Am 35(11):698-705

10. Nakatani T, Ura T, Ito Y, Kojima J, Tamura K, Sakamaki T, Nose Y (2008) AUV "TUNA-SAND" and its exploration of hydrothermal vents at Kagoshima Bay. OCEANS 2008-MTS/ IEEE Kobe Techno-Ocean, pp 1-5

11. Szeliski R (2010) Computer vision: algorithms and applications. Springer, London

12. McGlamery BL (1980) A computer model for underwater camera systems. Ocean optics VI. Int Soc Opt Photonics 221-231

13. Jaffe JS (1990) Computer modeling and the design of optimal underwater imaging systems. IEEE J Ocean Eng 101-111

14. Yamashita A, Fujii M, Kaneko T (2007) Color registration of underwater images for underwater sensing with consideration of light attenuation. In: IEEE international conference on robotics and automation, pp 4570-4575

15. Bazeille S, Quidu I, Jaulin L, Malkasse JP (2006) Automatic underwater image pre-processing. CMM'06, pp 1-8

16. Singh H, Roman C, Pizarro O, Eustice R, Can A (2007) Towards high-resolution imaging from underwater vehicles. Int $\mathrm{J}$ Robot Res 26(1):55-74

17. Land EH, McCann JJ (1971) Lightness and retinex theory. JOSA 61(1):1-11

18. Rahman Z, Jobson DJ, Woodell GA (2004) Retinex processing for automatic image enhancement. J Electron Imaging 13(1):100-110

19. Csurka G, Dance C, Fan L, Willamowski J, Bray C (2004) Visual categorization with bags of keypoints. Workshop on statistical learning in computer vision, pp 1-16

20. Lowe DG (2004) Distinctive image features from scale-invariant keypoints. Int J Comput Vis 91-110 